\title{
Preparation and structural characterization of lignin micro/nano-particles with ionic liquid treatment by self-assembly
}

\author{
C. $\operatorname{Liu}^{1,2}, Y . M . \operatorname{Li}^{1,2}, Y . \operatorname{Hou}^{1,2^{*}}$ \\ ${ }^{1}$ State Key Laboratory of Pulp and Paper Engineering, South China University of Technology, 510640 Guangzhou, China \\ ${ }^{2}$ National Engineering Research Center of Papermaking and Pollution Control, South China University of Technology, \\ 510640 Guangzhou, China
}

Received 20 March 2018; accepted in revised form 31 May 2018

\begin{abstract}
In the present research, 1,3-dimethyl-imidazolium dimethyl phosphate ([Mmim][DMP]) ionic liquid was applied to dissolve alkali lignin from wheat grass to prepare for lignin micro/nano-particles. The alkali lignin can be dissolved completely at $80^{\circ} \mathrm{C}$ in 30 min under microwave condition with [Mmim][DMP] (solid-liquid ratio of 1:10) which is easy to be recycled. The dissolved lignin can be precipitated by diluting the ionic liquid-lignin solution with water to get lignin micro/nano-particles with diameter ranged from $200 \mathrm{~nm}$ to $1.5 \mu \mathrm{m}$. Structural analyses with Gel permeation chromatography (GPC), 2D heteronuclear single quantum coherence nuclear magnetic resonance (2D-NMR), Thermogravimetric Analysis (TGA), etc., indicate that a large number of dehydration reactions occurred during dissolution process to result in the generation of unsaturated bonds with higher degree of unsaturation $(\Omega)$ (from 197-334), lower polydispersity (from 1.49 to 1.12 ) and lower average molecular weight (from 8634 to $5406 \mathrm{Da}$ ). Compared with original alkali lignin, the regenerated alkali lignin as micro/nano-particles showed higher thermal stability. It was also found from the 2D NMR spectra that the cleavages of aryl-ether bonds dramatically happened during the dissolution process, [Mmim][DMP] ionic liquid is more likely to destroy lignin units linked by $\beta-\mathrm{O}-4^{\prime}$ bonds to G-type lignin with less steric hindrance, resulting in the least amount of $\beta-\mathrm{O}-4^{\prime}$ linkages. In addition, dehydration and demethylation of lignin occurred during the dissolution of ionic liquid.
\end{abstract}

Keywords: nanomaterials, ionic liquid, alkali lignin, dissolution, micro/nano-particles

\section{Introduction}

Lignin is one of the most abundant natural biopolymers on earth, which accounts for about $15-25 \mathrm{wt} \%$ of wood and is considered as a renewable source of aromatic and chemical feedstock $[1,2]$. As a complex and heterogeneous biomacromolecule, with primary monomers of guaiacyl (G), syringyl (S), and p-hydroxyphenyl $(\mathrm{H})$ connected by various interunit linkage such as $\beta-\mathrm{O}-4, \beta-\beta, \beta-5, \beta-1$, and $4-\mathrm{O}-5$, etc. $[3,4]$, lignin can be obtained as a byproduct from chemical pulping and biofuel production processes either in the form of valuable dispersing agent lignosulfonate or as kraft lignin, which nowadays is mainly burned as fuel during the chemical recovery process of kraft pulping [5, 6].

Lignin conversion into simple aromatic products is a difficult task due to lignin's recalcitrant nature, its complex structure, variability of sources and extraction processes $[7,8]$. It still takes a long way to realize the high value of lignin. Despite their usefulness, a comprehensive studies do have certain drawbacks namely high operating temperature and extended dissolution times are required for processing, (generally $>12 \mathrm{~h}$ ) etc. Therefore, it's necessary to develop

*Corresponding author, e-mail: ceyhou@scut.edu.cn (C) BME-PT 
low-temperature and rapid delignification with simplistic recovery of chemicals for advanced utilization of renewable and biodegradable lignin for a future bio-based economy. Recently ionic liquids (ILs) have been extensively used for the dissolution and delignification of biomass [9] with eco-friendly characteristics, being nonflammable and recyclable with low volatility and high thermal stability. More importantly, ionic liquids also have amphipathic properties which allows easy precipitation of dissolved lignin to form lignin micro/nano-particles by adding acid water (Acid deionized water).

In this paper, 1,3-dimethyl-imidazolium dimethyl phosphate ([Mmim][DMP $]$ ), which is known to have a good lignin solubility according to the researches by our team $[10,11]$, was employed to develop a rapid and complete alkali lignin dissolution method with low temperature and characterize the regenerated lignin micro/nano-particles by Fourier transform infrared spectroscopy (FT-IR), the elemental analysis, gel permeation chromatography (GPC), thermogravimetric analysis (TGA), 2D heteronuclear single quantum coherence nuclear magnetic resonance (2D HSQC NMR) spectroscopy. Furthermore characterization of regenerated lignin micro/nano-particles morphology was observed by scanning electron microscopy (SEM) and polarized light microscopy (PLM).

\section{Experimental}

\subsection{Materials}

Ionic liquid [Mmim][DMP] ( $\geq 99 \%)$ was made in the laboratory as previously described [12] with a yield of $97.5 \%$ and purity of $99.77 \%$. Water content (measured by Karl-Fischer titration) in the ionic liquid was $0.5 \mathrm{wt} \%$. Lignin (alkali lignin (Grass lignin) $\geq 99 \%$ purity) purchased from Sigma-Aldrich Company (Beijing, China). All other reagents used in the experiments were analytical grade.

\subsection{Solubility test for alkali lignin}

A microwave extraction apparatus (XH-100B, XINGHU Microwave BEIJING, China) was chosen to improve the efficiency of lignin dissolution in ionic liquids $[13,14]$. The dissolving conditions were as follows: microwave power, $500 \mathrm{~W}$; temperature, $80^{\circ} \mathrm{C}$; reaction time, $30 \mathrm{~min}$; and ratio of solid to liquid, 1:10. At the end of the preset reaction time, deionized water $\left(5-10^{\circ} \mathrm{C}\right)$ was added into the lignin-ionic liquid solution to terminate reaction of the regenerated lignin. More lignin can be obtained by adjusting the $\mathrm{pH}$ of the added water to $2-3$, using concentrated $\mathrm{H}_{2} \mathrm{SO}_{4}(96 \%)$. However, this strategy will pose a problem for further recycling of [Mmim][DMP]. Apart from visual observations the saturation point was also observed and confirmed using polarized light microscopy (PLM).

\subsection{Characterizations}

\subsubsection{Morphology of regenerated lignin}

Scanning electron microscopy (SEM; EV018, Carl Zeiss AG, Oberkochen, Germany) was used to observe the morphology of regenerated lignin in a vacuum. The samples were sputter-coated with gold to make the lignin conductive, avoiding degradation and buildup of charge on the specimen. The solidliquid reaction system was observed by perpendicular polarizing microscopy (PLM; DM2700M, Leica Microsystems GmbH, Wetzlar, Germany).The size of LM/NPs were measured by Static and dynamic laser light Scatterometer (ALV/CGS-3, Germany).

\subsubsection{Elemental analysis}

Elemental analysis was performed to determine the carbon, hydrogen, oxygen, and nitrogen content in lignin samples using US/CHNS-932 (LECO Corp., USA).

\subsubsection{Thermal characterization}

Thermogravimetric analysis was performed to compare the stability of the original alkali lignin (OAL) and lignin micro/nano-particles (LM/NPs) by a TAQ500 instrument (TA Company, New Castle, USA) in a nitrogen atmosphere, and a heating rate of $15^{\circ} \mathrm{C} / \mathrm{min}$ from 25 to $700^{\circ} \mathrm{C}$.

\subsubsection{Gel permeation chromatography (GPC)}

The lignin was acetylated with acetic anhydride/ pyridine $(1: 1 \mathrm{v} / \mathrm{v})$ at $70^{\circ} \mathrm{C}$ for $6 \mathrm{~h}$, and the derivatized lignin was dissolved in tetrahydrofuran (THF) and analyzed by a GPC max instrument (ViscotekRImax, Viscotek, UK) equipped with a PLgel $5 \mu \mathrm{m}$ MIXED-C column $(300 \times 7.5 \mathrm{~mm}$, VARIAN, Inc.) and PLgel $5 \mu \mathrm{m}$ guard column $(50 \times 7.5 \mathrm{~mm}$, VARIAN, Inc.) using UV-Vis detection (VE3210, Viscotek). To determine the molecular weight of the effluent, polystyrenes with a mass range between 580 and 3250000 Da were used to create a calibration curve. 


\subsubsection{Fourier transform infrared spectroscopy (FT-IR)}

FT-IR spectra were recorded on a Nicolet 6700 spectrometer (Vector 33, Bruker, Karlsruhe, Germany) operating in the wavelength range of $4000-650 \mathrm{~cm}^{-1}$. Each sample was coated by potassium bromide $(\mathrm{KBr})$ and formed into a pellet for analysis.

\subsubsection{NMR spectroscopy for dissolved lignin}

2D heteronuclear single quantum coherence nuclear magnetic resonance (2D HSQC NMR) spectra were acquired on a Bruker Avance $600 \mathrm{MHz}$ spectrometer fitted with a $5 \mathrm{~mm}$ gradient probe with inverse geometry (proton coils closest to the sample). $100 \mathrm{mg}$ of lignin sample was dissolved in $0.5 \mathrm{~mL}$ of DMSO- $d_{6}$. A recent published 2D HSQC NMR quantitative method was applied to estimate the lignin-coupling bond in hardwood and softwood samples [15]. The method uses a cluster of signals as an internal standard that are representative of all $\mathrm{C}_{9}$ units present in the sample. In this study, the quantitative method was applied with minor modification. For grass lignin (wheat grass lignin), the internal standard can thus be quantified by the total integration of the half syringyl signal $\left(S_{2,6}\right)$ plus the $G_{2}$ signal as well as half of the integration of $\mathrm{H}_{2,6}$ cross signal (Equation (1)):

$\mathrm{IC}_{9}$ units $=0.5 \mathrm{IS}_{2,6}+\mathrm{IG}_{2}+0,5 \mathrm{IH}_{2,6\left(\mathrm{IC}_{9}\right)}$

where $\mathrm{IS}_{2,6}$ is the integration of $\mathrm{S}_{2,6}$, and include $\mathrm{S}$ and $\mathrm{S}^{\prime} ; \mathrm{IG}_{2}$ is the integral value of $\mathrm{G}_{2} . \mathrm{IH}_{2,6}$ is the integral value of $\mathrm{H}_{2,6}$. $\mathrm{IC}_{9}$ represents the integral value of the aromatic ring. According to the internal standard $\left(\mathrm{IC}_{9}\right)$, the amount of IX [\%] could be obtained by Equation (2):

$\mathrm{IX}[\%]=\frac{\mathrm{IX}}{\mathrm{IC}_{9}} \cdot 100 \%$

where IX is the integral value of $\alpha$-position of $\mathrm{A}(\beta-\mathrm{O}-4), \mathrm{B}(\beta-\beta)$, and $\mathrm{C}(\beta-5)$; the integration should be conducted in the same contour level.

\section{Results and discussion}

\subsection{SEM and PLM observation}

The morphology of alkali lignin before and after treated by [Mmim][DMP] ionic liquid were confirmed by SEM and PLM images in Figure 1. and Figure 2. Interestingly, that nanoscale lignin particles formed through the self-assembly of dissolved lignin after dilution by water. From the image of PLM, the

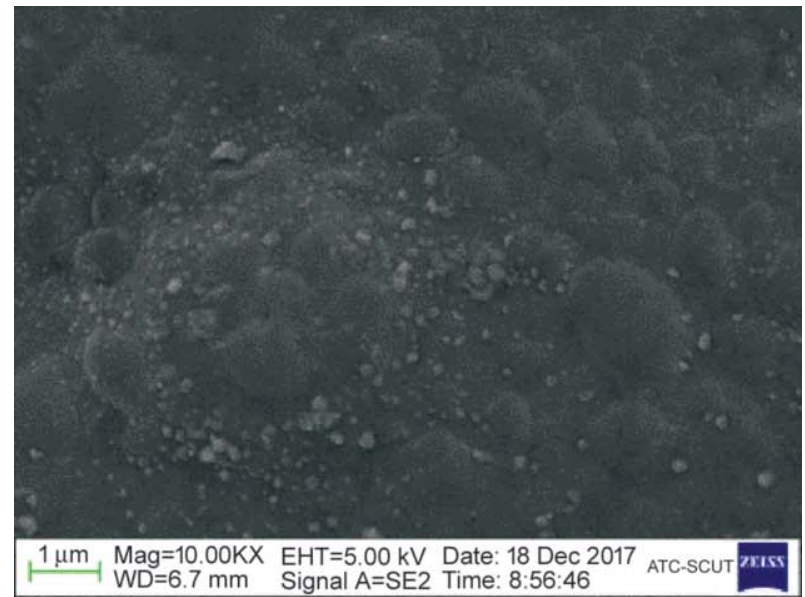

a)

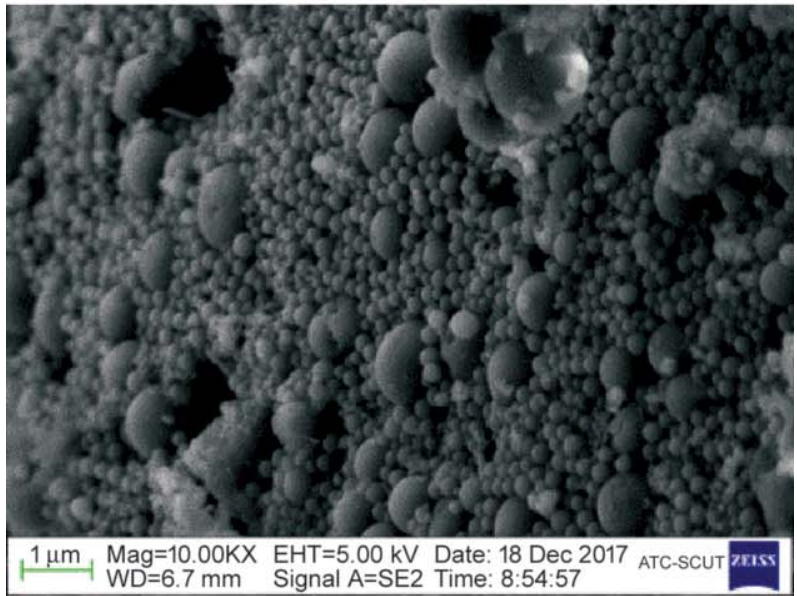

b)

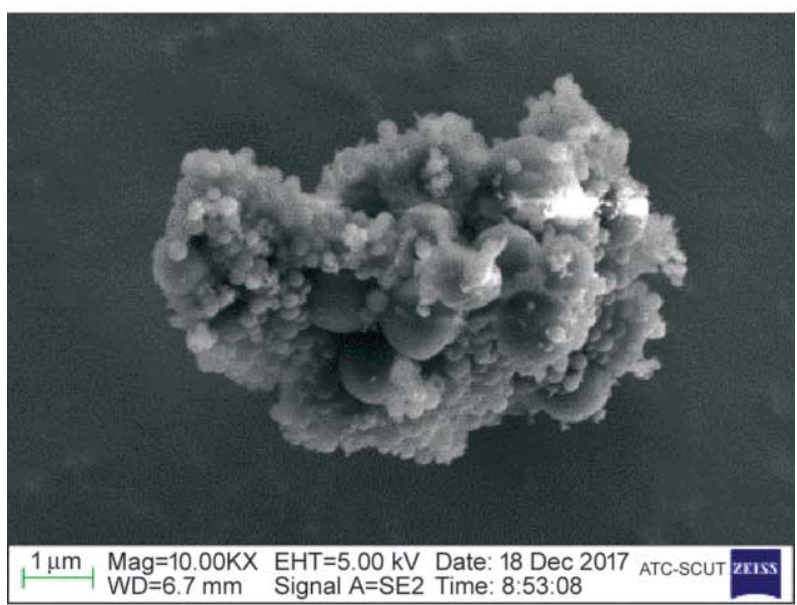

c)

Figure 1. SEM images of a) original alkali lignin, b), c) regenerated lignin micro/nano-particles.

fluorescent particles are lignin particles. The solid particles were composed of mainly small particles and a number of large particles with the size ranging from $200 \mathrm{~nm}$ to $1.5 \mu \mathrm{m}$, which agreed well with the particle size measured by the dynamic light scattering (DLS). And from the DLS, the large size particles may be due to the agglomeration of lignin 


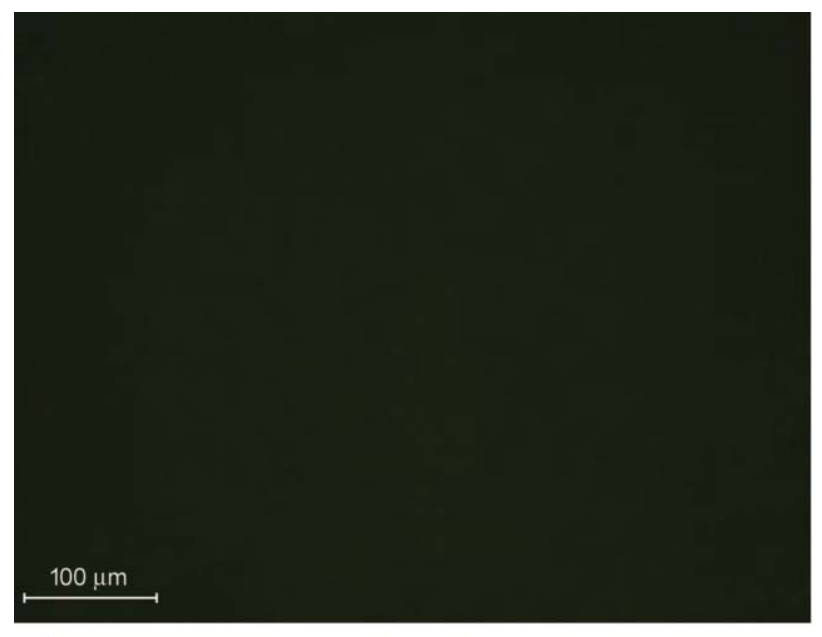

a)

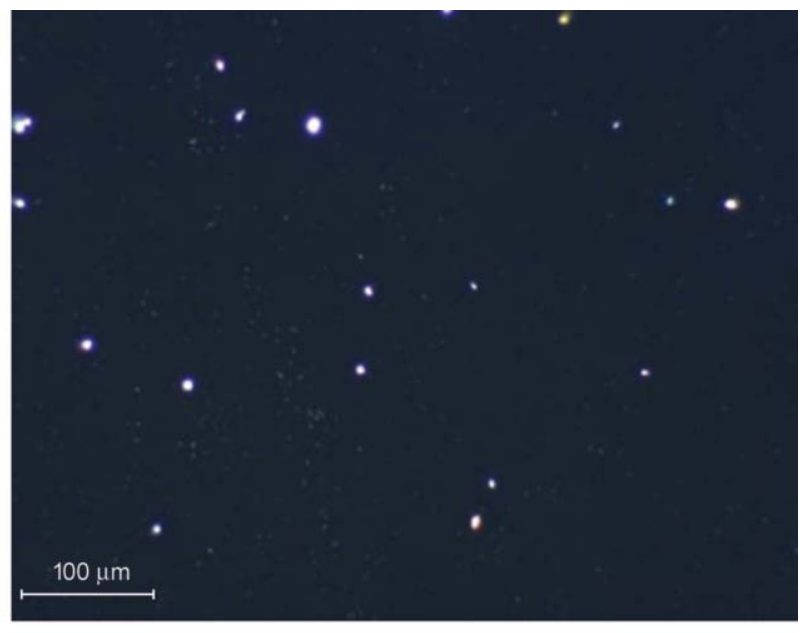

b)

Figure 2. PLM images of (a) all dissolving picture of alkali lignin, (b) lignin micro/nano-particles regenerated with water in $[\mathrm{Mmim}][\mathrm{DMP}]$.

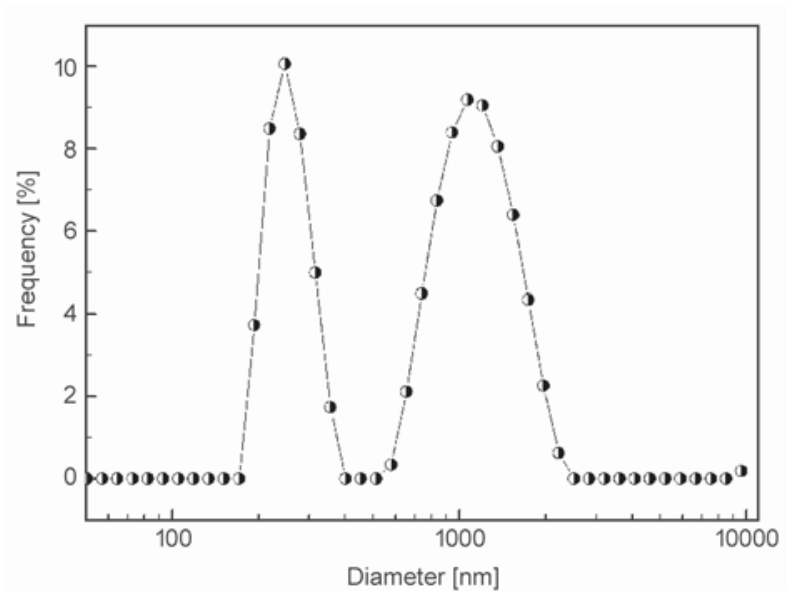

Figure 3. The size distribution of lignin micro/nano-particles.

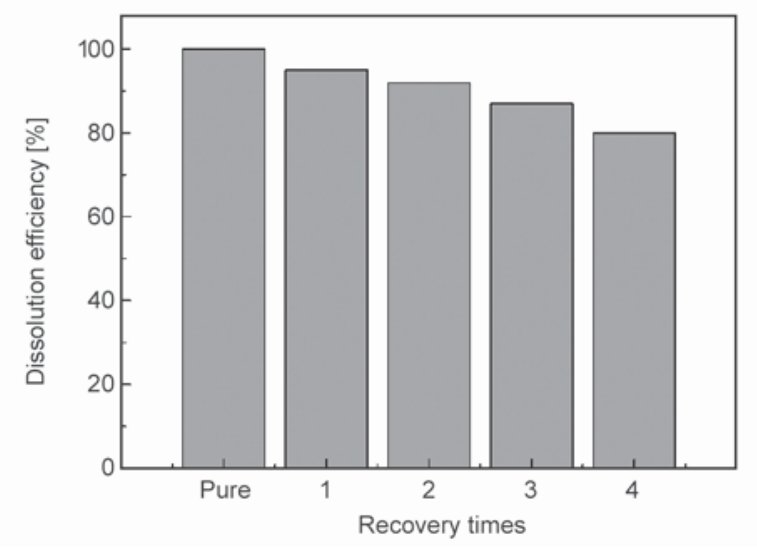

Figure 4. Lignin solubility in pure and recycled $[\mathrm{Mmim}][\mathrm{DMP}]$ ionic liquid. particles after centrifugation, drying and dispersed in the water (Figure 3).

Interests in using lignin micro/nano-particles for developing biodegradable materials are growing for many potential applications [16-18]. Many studies on lignin micro/nano-particles production used alkali lignin that was dissolved in organic solvents, such as ethylene glycol [18], acetone, tetrahydrofuran (THF) etc. Organic solvents bring an environmental concern and increases cost for solvent recovery. In contrast, [Mmim][DMP] ionic liquid can be recycled 3-5 times, the recovered mass of [Mmim][DMP] ionic liquid after recycling was found to be more than $95 \%$ (Figure 4.), which indicated a potentially well recyclable solvent.

\subsection{Elemental analysis}

Table 1 shows the elemental composition, $\mathrm{C}_{9}$ formula and degree of unsaturation of OAL and LM/NPs. The elemental carbon content of OAL $(26.5 \%)$ was determined to be obviously lower than that of LM/NPs (49.1\%), whereas the oxygen content of LM/NPs (43.1\%) was lower than that of OAL (66.1\%). This may be due to the large amount of dehydration and demethoxylation reactions that occurred during dissolution process, which is consistent with other literature reports [19].The relatively high nitrogen content $(2.1 \%)$ of LM/NPs was particularly notable,

Table1. Elemental composition, calculated $\mathrm{C}_{9}$ formula, and degree of unsaturation of original alkali lignin (OAL) and lignin micro/nano-particles (LM/NPs).

\begin{tabular}{|l|c|c|c|c|c|c|c|}
\hline \multicolumn{1}{|c|}{ Lignin } & $\begin{array}{c}\mathbf{C} \\
{[\%]}\end{array}$ & $\begin{array}{c}\mathbf{H} \\
{[\%]}\end{array}$ & $\begin{array}{c}\mathbf{O} \\
{[\%]}\end{array}$ & $\begin{array}{c}\mathbf{N} \\
{[\%]}\end{array}$ & $\begin{array}{c}\mathbf{S} \\
{[\%]}\end{array}$ & $\mathbf{C}_{\mathbf{9}}$ formula & $\begin{array}{c}\text { Degree of } \\
\text { unsaturation }\end{array}$ \\
\hline $\mathrm{OAL}$ & 26.5 & 3.5 & 66.1 & 0.6 & 3.3 & $\mathrm{C}_{900} \mathrm{H}_{1426} \mathrm{O}_{1683} \mathrm{~N}_{17} \mathrm{~S}_{42}$ & 197 \\
\hline $\mathrm{LM} / \mathrm{NPs}$ & 49.1 & 5.3 & 43.1 & 2.1 & 0.4 & $\mathrm{C}_{900} \mathrm{H}_{1165} \mathrm{O}_{592} \mathrm{~N}_{32} \mathrm{~S}_{3}$ & 334 \\
\hline
\end{tabular}


most of the nitrogen in the LM/NPs probably came from the solvent. Interestingly, the content of sulfur element is basically gone off after treatment by ionic liquid, from 3.3 to $0.4 \%$. The literature [20] reports that compared with macromolecule lignin, the sulfur content of small molecular weight lignin is higher. The components of the small molecular weight have some loss in the process of treatment by ionic liquid, which can reasonably explain the lower sulfur content in the LM/NPs. It is noteworthy that the unsaturation of the alkali lignin rises from 197 to 334, indicating the formation of unsaturated bonds during dissolution process which inferred a positive possibility for modifications.

\subsection{Molecular weight distribution}

The values of the weight-average $\left(M_{\mathrm{w}}\right)$, number-average $\left(M_{\mathrm{n}}\right)$ molecular weight, and the polydispersity index $\left(M_{\mathrm{w}} / M_{\mathrm{n}}\right)$ of OAL and LM/NPs, as revealed by GPC analysis, are shown in Table 2. The $M_{\mathrm{w}}$ of LM/NPs was determined to be $5406 \mathrm{Da}$, which was only $3 / 5$ of the $M_{\mathrm{w}}$ of OAL (8634 Da). This lower $M_{\mathrm{w}}$ value for LM/NPs is good evidence for lignin fragmentation by the ionic liquid. In contrast, the difference between the $M_{\mathrm{n}}$ values of both LM/NPs and OAL is relatively small. The polydispersity index $\left(M_{\mathrm{w}} / M_{\mathrm{n}}\right)$ of OAL and LM/NPs was calculated to be 1.49 and 1.12, respectively. This result indicates that

Table 2. Average molecular weight and polydispersity index $\left(M_{\mathrm{w}} / M_{\mathrm{n}}\right)$ of original alkali lignin $(\mathrm{OAL})$ and lignin micro/nano-particles (LM/NPs).

\begin{tabular}{|l|c|c|c|}
\hline \multicolumn{1}{|c|}{ Lignin } & $\begin{array}{c}\boldsymbol{M}_{\mathrm{w}} \\
{[\text { Daltons] }}\end{array}$ & $\begin{array}{c}\boldsymbol{M}_{\mathbf{n}} \\
{[\text { Daltons] }}\end{array}$ & $\boldsymbol{M}_{\mathbf{w}} / \boldsymbol{M}_{\mathbf{n}}$ \\
\hline OAL & 8634 & 5779 & 1.49 \\
\hline LM/NPs & 5406 & 4793 & 1.12 \\
\hline
\end{tabular}

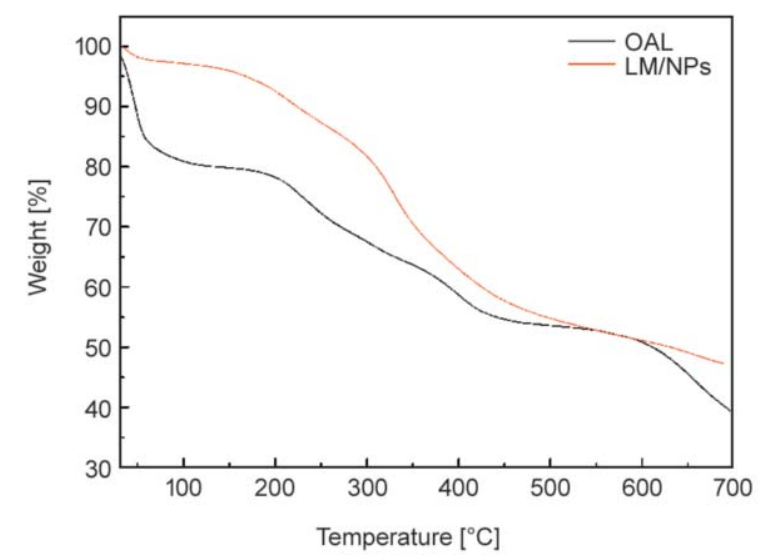

Figure 5. Thermogravimetric analysis of original alkali lignin (OAL) and lignin micro/nano-particles (LM/NPs). compared to OAL, LM/NPs was formed with a relatively uniform lignin fragment size and a lower number of condensed linkages.

\subsection{Thermal behavior}

Thermogravimetric (TGA) of OAL and LM/NPs are described in Figure 5. As to the OAL, may be due to the influence of the moisture, the weight loss of lignin before $100^{\circ} \mathrm{C}$ is larger. But the processing temperature for thermoplastic ploymers rises above $200^{\circ} \mathrm{C}$. The weight loss of thermal degradation of lignin samples is mainly distributed in the range of $200-450^{\circ} \mathrm{C}$, in which the lignin side chain bonds are cleaved and the benzene ring structure is degraded [21]. During dissolution process, the lignin degraded to a certain degree, the molecular weight decreased. Some condensation reactions occurred in the molecular or intramolecular, such as the formation of $\beta-5^{\prime}$ bonds, etc. Finally, the degradation rate of lignin at 200-450 ${ }^{\circ} \mathrm{Cwas}$ accelerated. The results of the TGA curves, indicates that the lignin obtained after dissolution and regeneration process with [Mmim][DMP] is thermally more stable than that of the original alkali lignin. In addition, lignin thermal decomposition of its carbon residue is proportional to the size of the molecular weight, which was consistent with the results obtained from molecular weight distribution.

\subsection{FT-IR spectra}

In the present study, FT-IR spectra of OAL and LM/NPs are illustrated in Figure 6. The absorption at $3385 \mathrm{~cm}^{-1}$ is due to the $\mathrm{O}-\mathrm{H}$ stretching and that at 2925 and $2852 \mathrm{~cm}^{-1}$ to the $\mathrm{C}-\mathrm{H}$ stretching. In the fingerprint region, between 1800 and $900 \mathrm{~cm}^{-1}$, many sharp and discrete absorption bands due to various functional groups present in LM/NPs and OAL were

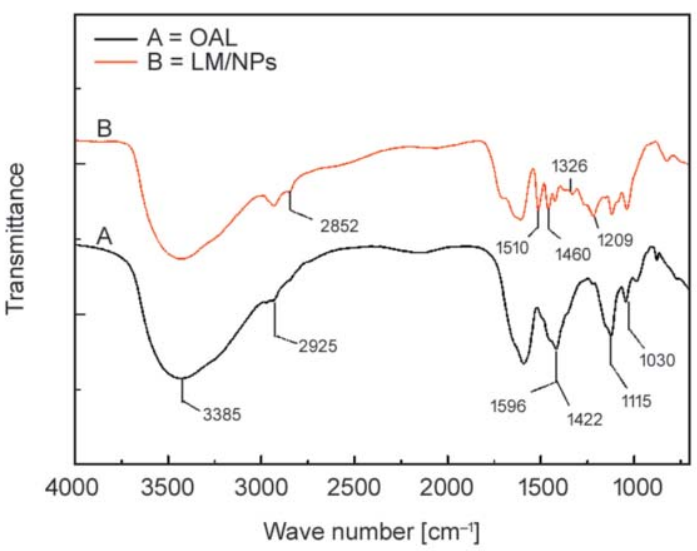

Figure 6. FTIR spectra for (A) original alkali lignin (OAL), (B) lignin micro/nano-particles (LM/NPs). 
Table 3. Band assignments for FTIR spectra.

\begin{tabular}{|c|l|}
\hline $\begin{array}{c}\text { Band } \\
{\left[\mathbf{c m}^{-1}\right]}\end{array}$ & \multicolumn{1}{c|}{ Assignment } \\
\hline 3385 & O-H vibrations \\
\hline 1596 & Aromatic skeletal vibration breathing with C=C stretching \\
\hline 1510 & Aromatic skeletal vibration \\
\hline 1460 & CH asymmetric deformation \\
\hline 1422 & Aromatic skeletal vibrations \\
\hline 1326 & Syringyl ring breathing with CO stretching \\
\hline 1209 & Guaicyl ring breathing with CO stretching \\
\hline 1115 & - CH in plane deformation in syringyl ring \\
\hline 1030 & - CH in plane deformation in guaiacyl and CO deformation in primary alcohols \\
\hline
\end{tabular}

observed (Table 3). The bands for aromatic skeleton vibrations, assigned at $1596,1510,1460$, and $1422 \mathrm{~cm}^{-1}$, show the typical signal pattern expected for a lignin moiety. The band at $1209 \mathrm{~cm}^{-1}$ is assigned to guaicyl ring breathing with $\mathrm{CO}$ stretching, the band at $1326 \mathrm{~cm}^{-1}$ is associated with syringyl $(s)$ units and the band at $1115 \mathrm{~cm}^{-1}$ is $\mathrm{CH}$ in plane deformation in syringyl ring. In addition, the occurrence of the intensive peak at $1030 \mathrm{~cm}^{-1}$ is due to the aromatic $\mathrm{C}-\mathrm{H}$ in-plane deformation were visible in both lignin spectra. On the whole, as can be seen from the spectra, some changes have occurred in the LM/NPs structural units. There is an increased proportion of G-type structure of LM/NPs, which was consistent

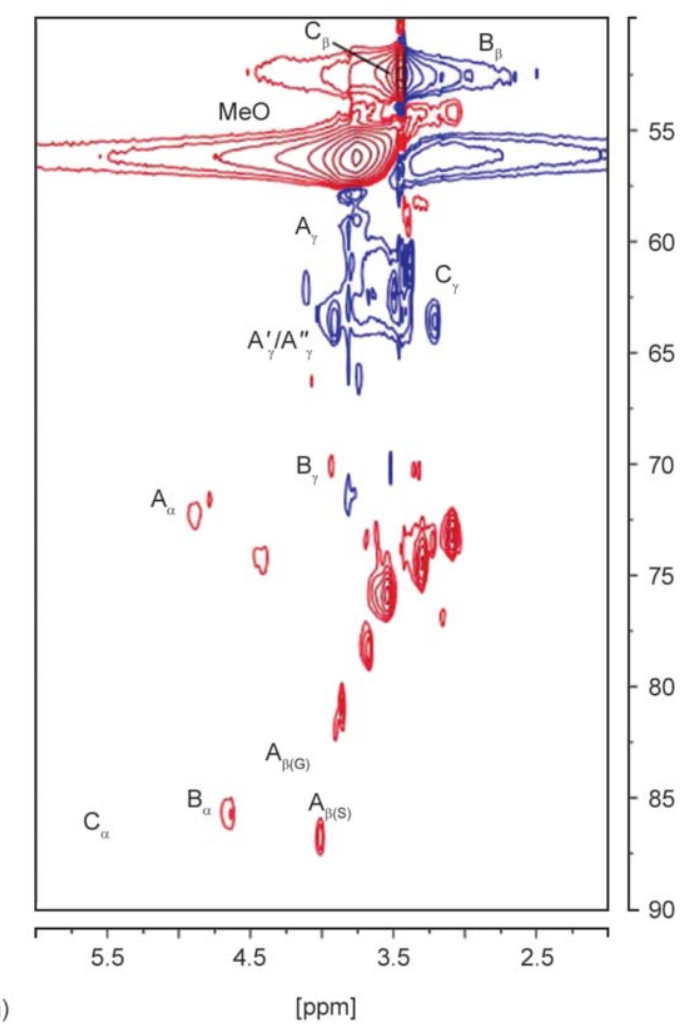

with the results obtained from 2D-HSQC NMR spectra. This also indicates that the breakage of chemical bonds in the lignin macromolecules resulted in changes in the number of $\mathrm{G}$ and $\mathrm{S}$ lignin molecules.

\subsection{D-HSQC NMR spectra}

To further investigate structural changes of lignin during ionic liquid dissolution process, the OAL and LM/NPs were comparatively characterized by the 2D-HSQC NMR technique. The side chain $\left(\delta_{\mathrm{C}} / \delta_{\mathrm{H}}\right.$ $90-50 / 6.0-2.0 \mathrm{ppm})$ and the aromatic regions $\left(\delta_{\mathrm{C}} / \delta_{\mathrm{H}}\right.$ 135-95/8-6) of the HSQC spectra are shown in Figures 7 and 8 . The main cross-signals assigned according to the literatures [22-24] are listed in Table 4.

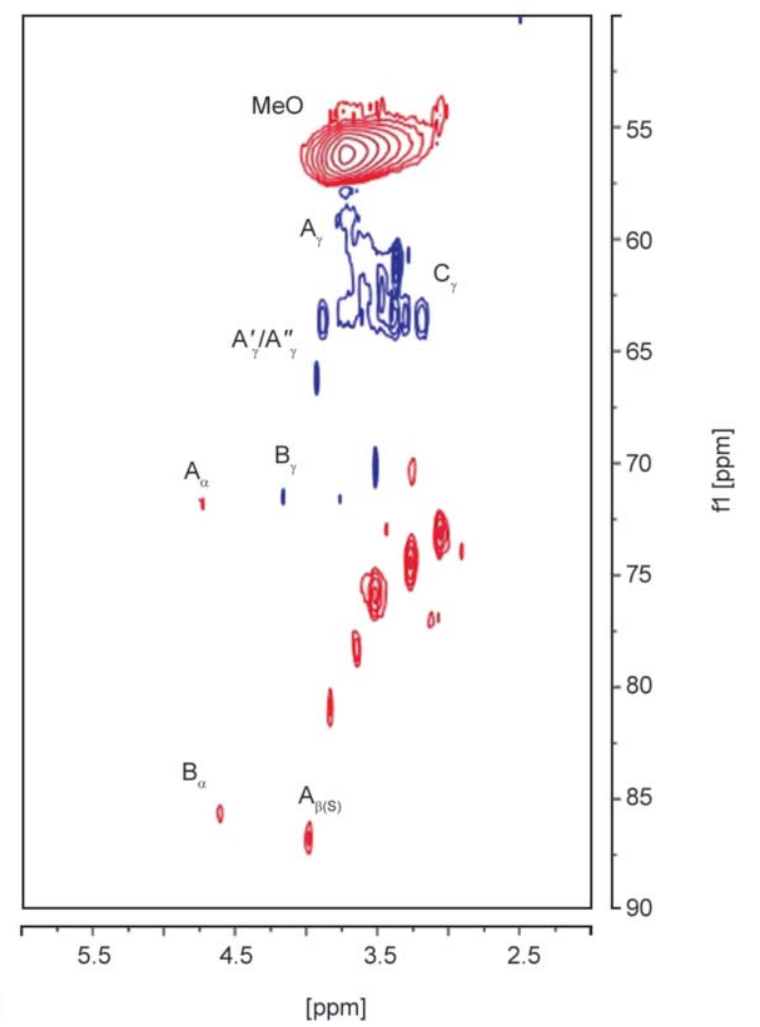

Figure 7. The side chain region of the HSQC spectrum of a) original alkali lignin, b) lignin micro/nano-particles 


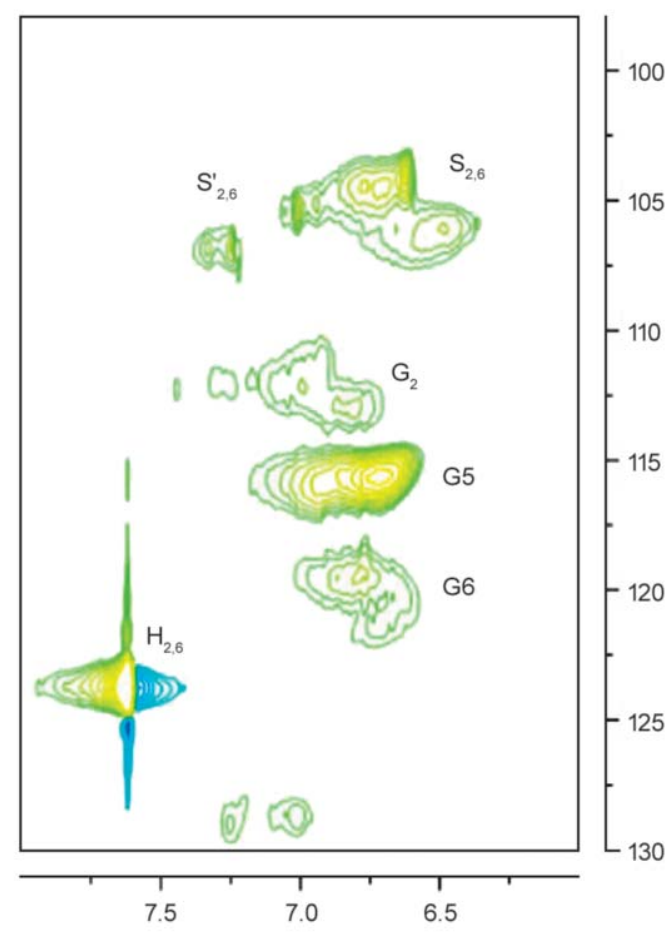

a)

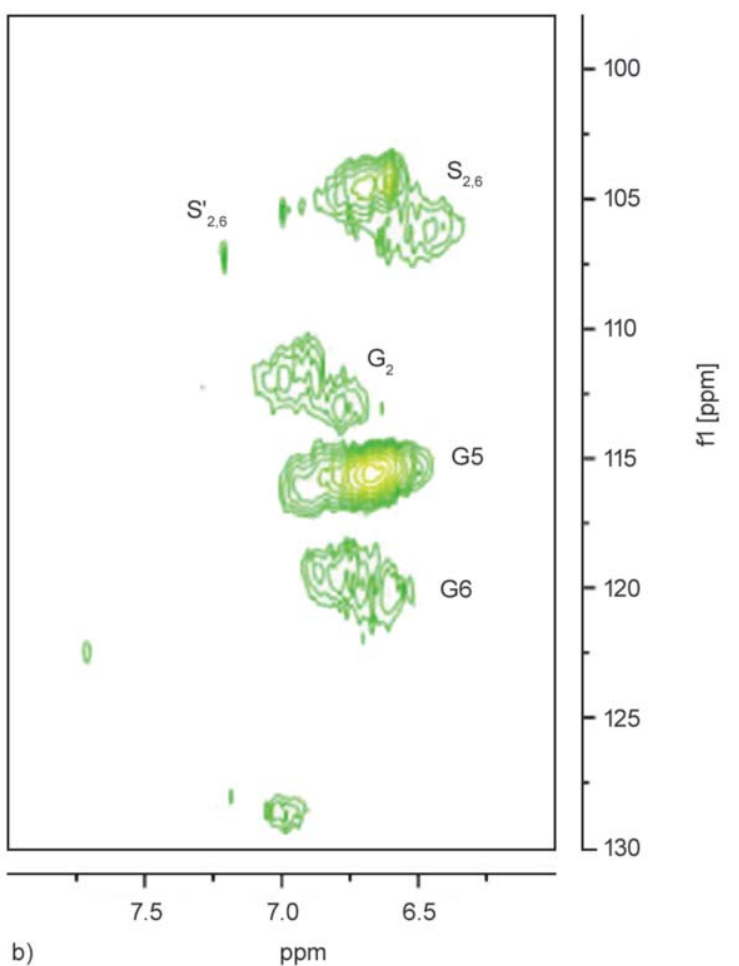

Figure 8. The aromatic region of the HSQC spectrum of a) original alkali lignin, b) lignin micro/nano-particles.

In the side-chain region of the lignin, cross-peaks of different interunit linkages were identified, such as $\beta$-aryl-ether $\left(\beta-\mathrm{O}-4^{\prime}, \mathrm{A}\right)$, resinol $\left(\beta-\beta^{\prime}, \mathrm{B}\right)$, and phenylcoumaran $\left(\beta-5^{\prime}, \mathrm{C}\right)$, and it can also be evidently observed that, the cross-signals of methoxy groups $\left(-\mathrm{OCH}_{3}, \delta_{\mathrm{C}} / \delta_{\mathrm{H}} 55.2 / 3.76 \mathrm{ppm}\right)$ and $\beta-\mathrm{O}-4^{\prime}$, A sub- structures (A) were the most prominent, $\mathrm{A}_{\alpha}$ and $\mathrm{A}_{\gamma}$ positions of which were presented at $\delta_{\mathrm{C}} / \delta_{\mathrm{H}} 72.0 / 4.88$ and 59.9/3.2-3.5 ppm. $C_{\beta}$ positions of $\beta-\mathrm{O}-4^{\prime}$ in $\mathrm{G}$ and $\mathrm{S}$ type lignins were also detected at $\delta_{\mathrm{C}} / \delta_{\mathrm{H}}$ $83.7 / 4.31$ and $86.3 / 4.01 \mathrm{ppm}$, respectively. In these lignin samples, a clear signal at $\delta_{\mathrm{C}} / \delta_{\mathrm{H}} 63.9 / 3.91 \mathrm{ppm}$

Table 4. Assignments of ${ }^{13} \mathrm{C}-{ }^{1} \mathrm{H}$ correlation signals in the HSQC NMR spectrum of original alkali lignin (OAL) and lignin micro/nano-particles (LM/NPs).

\begin{tabular}{|c|c|c|}
\hline Labels & $\begin{array}{c}\boldsymbol{\delta}_{\mathrm{C}} / \boldsymbol{\delta}_{\mathrm{H}} \\
{[\mathrm{ppm}]}\end{array}$ & Assignment \\
\hline $\mathrm{B}_{\beta}$ & $53.7 / 3.07$ & $\mathrm{C}_{\beta}-\mathrm{H}_{\beta}$ in $\beta-\beta^{\prime}$ (resinol) substructures (B) \\
\hline $\mathrm{C}_{\beta}$ & $53.9 / 3.45$ & $\mathrm{C}_{\beta}-\mathrm{H}_{\beta}$ in phenylcoumaran substructures $(\mathrm{C})$ \\
\hline $\mathrm{MeO}$ & $55.2 / 3.76$ & $\mathrm{C}-\mathrm{H}$ in methoxyls \\
\hline $\mathrm{A}_{\gamma}$ & $59.9 / 3.2-3.5$ & $\mathrm{C}_{\gamma}-\mathrm{H}_{\gamma}$ in $\beta-\mathrm{O}-4^{\prime}$ substructures (A) \\
\hline $\mathrm{C}_{\gamma}$ & $63.5 / 3.65$ & $\mathrm{C}_{\gamma}-\mathrm{H}_{\gamma}$ in phenylcoumaran substructures $(\mathrm{C})$ \\
\hline $\mathrm{A}_{\gamma}^{\prime} / \mathrm{A}_{\gamma}^{\prime \prime}$ & $63.9 / 3.91$ & $\mathrm{C}_{\gamma}-\mathrm{H}_{\gamma}$ in $g$-acylated $/ g$ - $p$-coumaroylated $\beta-\mathrm{O}-4^{\prime}$ substructures $\left(\mathrm{A}^{\prime} / \mathrm{A}^{\prime \prime}\right)$ \\
\hline $\mathrm{B}_{\gamma}$ & $70.9 / 3.77,4.15$ & $\mathrm{C}_{\gamma}-\mathrm{H}_{\gamma}$ in $\beta-\beta^{\prime}$ resinol substructures (B) \\
\hline $\mathrm{A}_{\alpha}$ & $72.0 / 4.88$ & $\mathrm{C}_{\alpha}-\mathrm{H}_{\alpha}$ in $\beta-\mathrm{O}-4^{\prime}$ substructures linked to an $\mathrm{S}$ units (A) \\
\hline $\mathrm{A}_{\beta(\mathrm{G})}$ & $83.7 / 4.31$ & $\mathrm{C}_{\beta}-\mathrm{H}_{\beta}$ in $\beta-\mathrm{O}-4^{\prime}$ substructures linked to $\mathrm{G}$ and $\mathrm{H}$ units (A) \\
\hline $\mathrm{B}_{\alpha}$ & $85.7 / 4.63$ & $\mathrm{C}_{\alpha}-\mathrm{H}_{\alpha}$ in $\beta-\mathrm{O}-4^{\prime}$ (resinol) substructures (B) \\
\hline$A_{\beta(s)}$ & $86.3 / 4.01$ & $\mathrm{C}_{\beta}-\mathrm{H}_{\beta}$ in $\beta-\mathrm{O}-4^{\prime}$ substructures linked to $\mathrm{S}$ units (A) \\
\hline $\mathrm{C}_{\alpha}$ & $86.9 / 5.5$ & $\mathrm{C}_{\alpha}-\mathrm{H}_{\alpha}$ in phenylcoumaran substructures $(\mathrm{C})$ \\
\hline $\mathrm{S}_{2,6}$ & $104.2 / 6.62$ & $\mathrm{C}_{2,6}-\mathrm{H}_{2,6}$ in $\mathrm{S}$ units $(\mathrm{S})$ \\
\hline $\mathrm{S}_{2,6}^{\prime}$ & $106.7 / 7.24$ & $\mathrm{C}_{2,6}-\mathrm{H}_{2,6}$ in $\mathrm{C}_{\alpha}$-oxidized $\mathrm{S}$ units $\left(\mathrm{S}^{\prime}\right)$ \\
\hline $\mathrm{G}_{2}$ & $111.4 / 6.95$ & $\mathrm{C}_{2}-\mathrm{H}_{2}$ in $\mathrm{G}$ units $(\mathrm{G})$ \\
\hline $\mathrm{G}_{2}^{\prime}$ & $109.0 / 7.15$ & $\mathrm{C}_{2}-\mathrm{H}_{2}$ in $\mathrm{C}_{\alpha}$-oxidized $\mathrm{G}$ units $\left(\mathrm{G}^{\prime}\right)$ \\
\hline $\mathrm{G}_{5}$ & $115.1 / 6.7$ & $\mathrm{C}_{5}-\mathrm{H}_{5}$ in $\mathrm{G}$ units $(\mathrm{G})$ \\
\hline $\mathrm{G}_{6}$ & $119.3 / 6.78$ & $\mathrm{C}_{6}-\mathrm{H}_{6}$ in $\mathrm{G}$ units $(\mathrm{G})$ \\
\hline $\mathrm{H}_{2,6}$ & $123.79 / 7.57$ & $\mathrm{C}_{2,6}-\mathrm{H}_{2,6}$ in $\mathrm{H}$ units $(\mathrm{H})$ \\
\hline
\end{tabular}




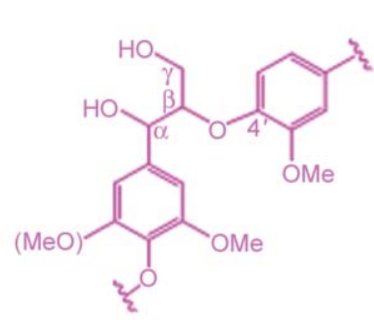

A

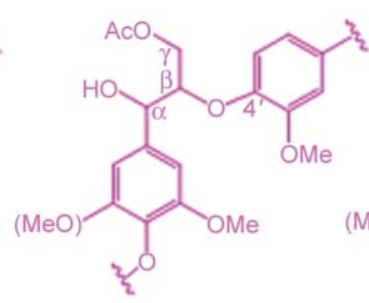

$A^{\prime}$

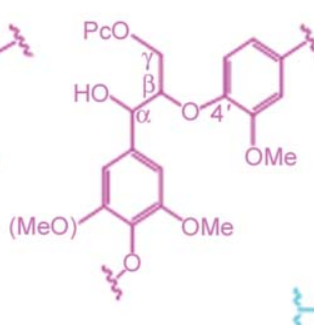

A"

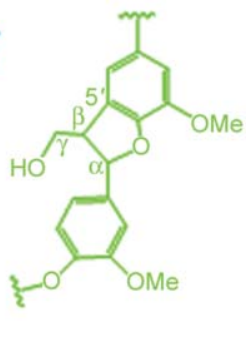

C

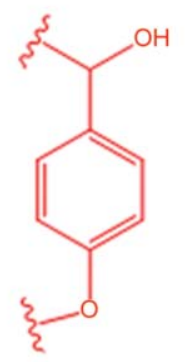

$\mathrm{H}$

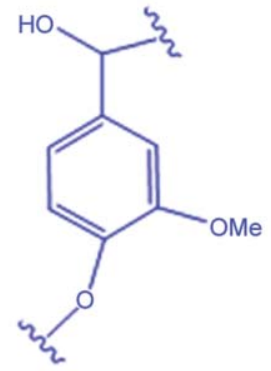

G

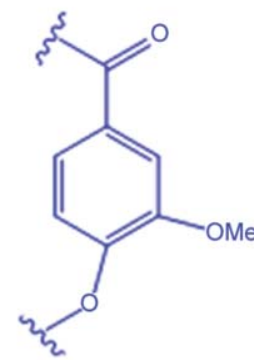

$G^{\prime}$

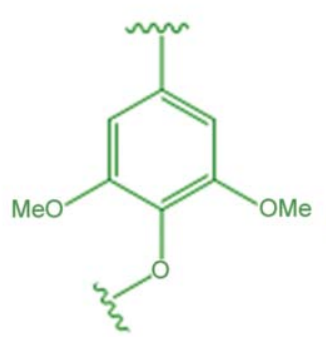

S

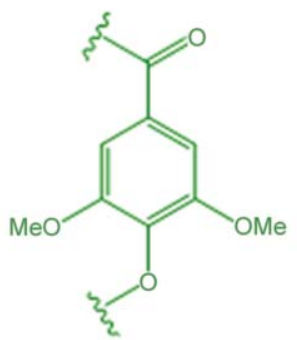

$\mathrm{S}^{\prime}$

Figure 9. Main substructures observed in grass lignin: (A) $\beta-\mathrm{O}-4^{\prime}$ linkages; ( $\left.\mathrm{A}^{\prime}\right) \beta-\mathrm{O}-4^{\prime}$ linkages with acetylated at $\gamma$-carbon; $\left(\mathrm{A}^{\prime \prime}\right) \gamma-p$-coumaroylated $\beta-\mathrm{O}-4^{\prime}$ linkages; (B) resinol formed by $\beta-\beta^{\prime}, \alpha-\mathrm{O}-\gamma^{\prime}$, and $\gamma-\mathrm{O}-\alpha^{\prime}$ linkages; (C) phenylcoumaran structures formed by $\beta-5^{\prime}$ and $\alpha-\mathrm{O}-4^{\prime}$ linkages; $(\mathrm{G})$ guaiacyl units; $\left(\mathrm{G}^{\prime}\right)$ oxidized guaiacyl units with a $\mathrm{C}_{\alpha}$ ketone; (S) syringyl units; ( $\left.\mathrm{S}^{\prime}\right)$ oxidized syringyl units with a $\mathrm{C}_{\alpha}$ ketone; $(\mathrm{H})$-hydroxyphenyl units.

assigned to $\mathrm{C}_{\gamma} / \mathrm{H}_{\gamma}$ correlations in $\gamma$-oxidized lignin units $\left(\mathrm{A}_{\gamma}^{\prime} / \mathrm{A}_{\gamma}{ }_{\gamma}\right)$ was also identified. Signals for resinol substructures $\left(\beta-\beta^{\prime}, B\right)$ were observed in all the HSQC spectra, with their $\mathrm{C}_{\alpha} / \mathrm{H}_{\alpha}, \mathrm{C}_{\beta} / \mathrm{H}_{\beta}$, and double $\mathrm{C}_{\gamma} / \mathrm{H}_{\gamma}$ correlations at $\delta_{\mathrm{C}} / \delta_{\mathrm{H}} 85.7 / 4.63,53.7 / 3.07$ and 70.9/3.77,4.15 ppm, respectively. Phenylcoumaran substructures $(\beta-5 / \alpha-\mathrm{O}-4, \mathrm{C})$ were distinguished in the signals for their $\mathrm{C}_{\alpha} / \mathrm{H}_{\alpha}$ and $\mathrm{C}_{\beta} / \mathrm{H}_{\beta}$, correlations being presented at $\delta_{\mathrm{C}} / \delta_{\mathrm{H}} 86.9 / 5.5$ and 53.9/3.45 ppm, and that of $\mathrm{C}_{\gamma} / \mathrm{H}_{\gamma}$ correlation overlapping with xylan $\mathrm{C}_{5} / \mathrm{H}_{5}$ cross-signals around $\delta_{\mathrm{C}} / \delta_{\mathrm{H}} 63.5 / 3.65 \mathrm{ppm}$. The NMR spectrum of lignin dissolved with ionic liquid treatment indicates that the LM/NPs has clear structure changes in comparison to the OAL, and the intensity of these signals in OAL is stronger than in LM/NPs (Figure 9).

In the aromatic region $\left(\delta_{\mathrm{C}} / \delta_{\mathrm{H}} 95-130 / 6.0-8.0 \mathrm{ppm}\right)$, the main cross-signals from the aromatic rings of guaiacyl $(\mathrm{G})$, syringyl $(\mathrm{S})$ and $p$-hydroxyphenyl $(\mathrm{H})$ were clearly observed in the spectra. The $\mathrm{S}$ units showed a prominent signal for the $\mathrm{C}_{2,6}-\mathrm{H}_{2,6}$ correlation at $\delta_{\mathrm{C}} / \delta_{\mathrm{H}} 104.2 / 6.62 \mathrm{ppm}$, and the signal corresponding to $\mathrm{C}_{2,6}-\mathrm{H}_{2,6}$ correlations in $\mathrm{C} \alpha$-oxidized $\mathrm{S}$ units $\left(\mathrm{S}^{\prime}\right)$ was indentified at $\delta_{\mathrm{C}} / \delta_{\mathrm{H}} 106.7 / 7.24 \mathrm{ppm}$. In addition, the $\mathrm{G}$ units showed different correlations of $\mathrm{C}_{2}-\mathrm{H}_{2}\left(\delta_{\mathrm{C}} / \delta_{\mathrm{H}} 111.4 / 6.95 \mathrm{ppm}\right), \mathrm{C}_{5} / \mathrm{H}_{5}\left(\delta_{\mathrm{C}} / \delta_{\mathrm{H}}\right.$
$115.1 / 6.7)$, and $\mathrm{C}_{6} / \mathrm{H}_{6}\left(\delta_{\mathrm{C}} / \delta_{\mathrm{H}} 119.3 / 6.78 \mathrm{ppm}\right)$. In addition, a clear signal for the $\mathrm{C}_{2,6}-\mathrm{H}_{2,6}$ correlation at $\delta_{\mathrm{C}} / \delta_{\mathrm{H}} 123.79 / 7.57 \mathrm{ppm}$ originating from $p$-hydroxyphenyl $(\mathrm{H})$ lignin units was detected in OAL. Therefore, the lignin was mainly composed of guaiacyl and syringyl units with minor amounts of p-hydroxyphenyl unit. This conforms to the structure of the grass lignin. The contours of $\mathrm{S}, \mathrm{G}$ and $\mathrm{H}$ units substantially shrank, probably caused by lignin condensation at the 2-, 5-, and 6-positions because any new aromatic linkages at these positions would lack hydrogens and would be consequently invisible in the HSQC correlation spectra. The results indicate that the $[\mathrm{Mmim}][\mathrm{DMP}]$ ionic liquid treatment effectively depolymerized the lignin and also led to lignin condensation.

In order to compare the quantitative structural features of the OAL and LM/NPs, the number of specific structures per aromatic ring and the $\mathrm{G} / \mathrm{S}$ ratios was obtained by integrating the contour signals [25], and the results are listed in Table 5. In general, the arylglycerol- $b$-aryl ether linkage $(\beta-\mathrm{O}-4)$ is considered to be a typical linkage type in lignin macromolecules. The frequency of the $\beta-\mathrm{O}-4$ linkage accounts for $40-65 \%$ of the various coupling patterns and greatly affects the chemical and physical properties 
Table 5. Amount of inter-unit Linkages ( $\%$ of $\mathrm{C}_{9}$ units) in original alkali lignin (OAL) and lignin micro/nanoparticles (LM/NPs) by integration of of ${ }^{13} \mathrm{C}-{ }^{1} \mathrm{H}$ correlation signals in the HSQC spectra.

\begin{tabular}{|l|r|r|}
\hline $\begin{array}{c}\text { Linkage relative abundance } \\
\text { [\%] }\end{array}$ & OAL & LM/NPs \\
\hline$\beta-\mathrm{O}-4^{\prime}$ aryl ethers $(\mathrm{A})$ & 46.10 & 42.80 \\
\hline Resinols $\left(\beta-\beta^{\prime}, \mathrm{B}\right)$ & 9.41 & 6.14 \\
\hline Phenylcoumarans $\left(\beta-5^{\prime}, \mathrm{C}\right)$ & 6.34 & 5.52 \\
\hline G/S ratio & 2.11 & 3.05 \\
\hline
\end{tabular}

of the lignin [8]. In this study the lignin shared a common characteristic of a relatively higher proportion of $\beta-\mathrm{O}-4^{\prime}$ ether linkages and a lower proportion of carbon-carbon linkages (i.e., $\beta-\beta^{\prime}, \beta-5^{\prime}$ ). The number of these linkages is reduced by ionic liquid treatment, of which $\beta-\mathrm{O}-4^{\prime}$ is the most significant. The G/S ratio of OAL (2.11) was obviously lower than that of LM/NPs (3.05), indicating that the Gtype lignin was more easily extracted than the S-type lignin, during treatment with ionic liquid.

\subsection{Formation mechanism of lignin micro/nano-particles}

Previous studies have proposed that alkali lignin trends to form molecular aggregates [26, 27], and the $\pi-\pi$ interaction of the aromatic rings has been reported to be responsible for lignin association phenomena in organic solvents. The possible formation mechanism of lignin micro/nano-particles in ionic liquids can be obtained through the above research is presented in Figure 10. In the case of alkali lignin, the hydrogen bonding between hydroxyl groups and the intermolecular and intramolecular aggregation caused by $\pi-\pi$ interaction are more intense, and therefore they coexist in the form of single molecules and aggregates in solution. And the shape of the single molecule is more distorted. The hydrophobic chains of the complexes continue to aggregate to form a stable micro/nano-particle core when deionized water is added to the solution. And the ionic liquid
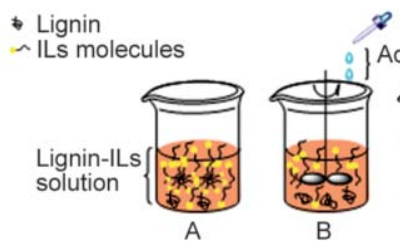

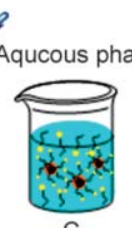

C

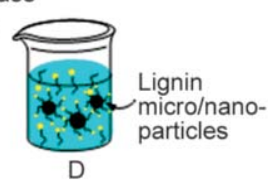

Figure 10. Preparation of lignin micro/nano-particles a) dissolve b) intermix c) aggregation d) solidification, centrifugation. molecules now acting as a surfactant with a weaker hydrophobicity are still dispersed in solution. With the further increase of deionized water, micro/ nanoparticles composed of a hydrophilic shell and a hydrophobic core are formed. This unique self-assembly method does not require the use of a surfactant, environmentally friendly, the process is simple, and its particle size can be controlled by adjusting the stirring speed and the dripping speed. Our group will continue to report on follow-up research.

\section{Conclusions}

1. Alkali lignin (solid-liquid ratio of 1:10) can be dissolved completely at $80^{\circ} \mathrm{C}$ in 30 min under microwave condition with [Mmim][DMP] which is easy to be recycled, lignin micro/nano-particles (LM/NPs) with diameter ranged from $200 \mathrm{~nm}$ to $1.5 \mu \mathrm{m}$ can be easily obtained by diluting ionic liquid-lignin solution with water. The micro/nanoparticles possess hydrophilic shells and hydrophobic cores which show very good stability in acidic conditions.

2. Characterization of the LM/NPs showed much lower polydispersity and unsaturation, the average molecular weight was reduced 8634 to $5406 \mathrm{Da}$ with better thermal stability. Furthermore, the cleavage of the $\beta-\mathrm{O}-4$ ' linkage, degradation of $\beta-$ $\beta^{\prime}$ and $\beta-5^{\prime}$ linkages as well as demethoxylation reactions occurred in this dissolution process. The higher $\mathrm{G} / \mathrm{S}$ ratio of LM/NPs (3.05) indicates Gtype lignin was more extractable than S-type lignin during the dissolution process which also indirectly proves the occurrence of demethoxylation.

\section{Acknowledgements}

The authors are grateful for the support of the National key R\&D project of China (grant number 2017YFB0307901) and National Natural Science Foundation of China (grant number 21476091). The authors also appreciate the financial support from the Science and Technology Planning Project of Guangdong Province (grant number 2015A020215009) and the Science and Technology Planning Project of FoShan in Guangdong Province (grant number 2015AG10011).

\section{References}

[1] Rashid T., Kait C. F., Regupathi I., Murugesan T.: Dissolution of kraft lignin using protic ionic liquids and characterization. Industrial Crops and Products, 84, 284-293 (2016).

https://doi.org/10.1016/j.indcrop.2016.02.017 
[2] Geng X., Zhang Y., Jiao L., Yang L., Hamel J., Giummarella N., Henriksson G., Zhang L., Zhu H.: Bioinspired ultrastable lignin cathode via graphene reconfiguration for energy storage. ACS Sustainable Chemistry and Engineering, 5, 3553-3561 (2017).

https://doi.org/10.1021/acssuschemeng.7b00322

[3] Chatel G., Rogers R. D.: Review: Oxidation of lignin using ionic liquids - An innovative strategy to produce renewable chemicals. ACS Sustainable Chemistry and Engineering, 2, 322-339 (2014).

https://doi.org/10.1021/sc4004086

[4] Wu M., Liu J-K., Yan Z-Y., Wang B., Zhang X-M., Xu F., Sun R-C.: Efficient recovery and structural characterization of lignin from cotton stalk based on a biorefinery process using a $\gamma$-valerolactone/water system. RSC Advances, 6, 6196-6204 (2016).

https://doi.org/10.1039/c5ra23095k

[5] Milczarek G., Inganäs O.: Renewable cathode materials from biopolymer/conjugated polymer interpenetrating networks. Science, 335, 1468-1471 (2012).

https://doi.org/10.1126/science.1215159

[6] Azadi P., Inderwildi O. R., Farnood R., King D. A.: Liquid fuels, hydrogen and chemicals from lignin: A critical review. Renewable and Sustainable Energy Reviews, 21, 506-523 (2013).

https://doi.org/10.1016/j.rser.2012.12.022

[7] Tran F., Lancefield C. S., Kamer P. C. J., Lebl T., Westwood N. J.: Selective modification of the $\beta-\beta$ linkage in DDQ-treated Kraft lignin analysed by 2D NMR spectroscopy. Green Chemistry, 17, 244-249 (2014). https://doi.org/10.1039/C4GC01012D

[8] Nimz D. H.: Beech lignin - Proposal of a constitutional scheme. Angewandte Chemie International Edition, 13, 313-321 (2010). https://doi.org/10.1002/anie.197403131

[9] King A. W. T., Zoia L., Filpponen I., Olszewska A., Xie H., Kilpeläinen I., Argyropoulos D. S.: In situ determination of lignin phenolics and wood solubility in imidazolium chlorides using ${ }^{31} \mathrm{P}$ NMR. Journal of Agricultural and Food Chemistry, 57, 8236-8243 (2009). https://doi.org/10.1021/jf901095w

[10] Chen T., Li Y., Xu J., Hou Y.: Dissolution of eucalyptus powder with alkaline ionic liquid [Mmim] [DMP] under microwave conditions. Bioresources, 11, 9710-9722 (2016). https://doi.org/10.15376/biores.11.4.9710-9722

[11] Liu C., Li Y., Hou Y.: Basicity characterization of imidazolyl ionic liquids and their application for biomass dissolution. International Journal of Chemical Engineering, 2018, 7501659/1-7501659/8 (2018). https://doi.org/10.1155/2018/7501659

[12] Hou Y., Liu C., Xu J., Li Y., Hu S.: Application of alkaline ionic liquids in the pretreatment process of eucalyptus kraft pulping. Bioresources, 11, 9036-9046 (2016). https://doi.org/10.15376/biores.11.4.9036-9046
[13] Han D. H., Wei X. Y., Li J. H., Chen J. C., Cui L. H., Wang Y. H., Ou C. Y.: An orthogonal experiment of bagasse cellulose dissolution in ionic liquid by microwave heating. Advanced Materials Research, 602604, 676-680 (2013).

https://doi.org/10.4028/www.scientific.net/AMR.602-604.676

[14] Wang H., Maxim M. L., Gurau G., Rogers R. D.: Microwave-assisted dissolution and delignification of wood in 1-ethyl-3-methylimidazolium acetate. Bioresource Technology, 136, 739-742 (2013). https://doi.org/10.1016/j.biortech.2013.03.064

[15] Sette M., Wechselberger R., Crestini C.: Elucidation of lignin structure by quantitative 2D NMR. Chemistry A European Journal, 17, 9529-9535 (2011). https://doi.org/10.1002/chem.201003045

[16] Richter A. P., Brown J. S., Bharti B., Wang A., Gangwal S., Houck K., Hubal E. A. C., Paunov V. N., Stoyanov S. D., Velev O. D.: An environmentally benign antimicrobial nanoparticle based on a silver-infused lignin core. Nature Nanotechnology, 10, 817-823 (2015). https://doi.org/10.1038/nnano.2015.141

[17] Ten E., Ling C., Wang Y., Srivastava A., Dempere L. A., Vermerris W.: Lignin nanotubes as vehicles for gene delivery into human cells. Biomacromolecules, 15, 327338 (2014).

https://doi.org/10.1021/bm401555p

[18] Jiang C., He H., Jiang H., Ma L., Jia D. M.: Nano-lignin filled natural rubber composites: Preparation and characterization. Express Polymer Letters, 7, 480-493 (2013). https://doi.org/10.3144/expresspolymlett.2013.44

[19] Wen J-L., Yuan T-Q., Sun S-L., Xu F., Sun R-C.: Understanding the chemical transformations of lignin during ionic liquid pretreatment. Green Chemistry, 16, 181-190 (2013). https://doi.org/10.1039/c3gc41752b

[20] Sevastyanova O., Helander M., Chowdhury S., Lange H., Wedin H., Zhang L., Ek M., Kadla J. F., Crestini C., Lindström M. E.: Tailoring the molecular and thermomechanical properties of kraft lignin by ultrafiltration. Journal of Applied Polymer Science, 131, 9505-9515 (2014).

https://doi.org/10.1002/app.40799

[21] Fernandes D. M., Hechenleitner A. A. W., Pineda E. A. G.: Kinetic study of the thermal decomposition of poly(vinyl alcohol)/kraft lignin derivative blends. Thermochimica Acta, 441, 101-109 (2006).

https://doi.org/10.1016/j.tca.2005.11.006

[22] Ralph J., Hatfield R. D., Quideau S., Helm R. F., Grabber J. H., Jung H-J. G.: Pathway of $p$-coumaric acid incorporation into maize lignin as revealed by NMR. Journal of the American Chemical Society, 116, 94489456 (1994).

https://doi.org/10.1021/ja00100a006

[23] del Río J. C., Rencoret J., Gutiérrez A., Nieto L., Jiménez-Barbero J., Martínez Á. T.: Structural characterization of guaiacyl. Journal of Agricultural and Food Chemistry, 59, 11088-11099 (2011). https://doi.org/10.1021/jf201222r 
[24] Rencoret J., Marques G., Gutiérrez A., Ibarra D., Li J., Gellerstedt G., Santos J. I., Jiménez-Barbero J., Martínez Á. T., del Río J. C.: Structural characterization of milled wood lignins from different eucalypt species. Holzforschung, 62, 514-526 (2008).

https://doi.org/10.1515/HF.2008.096

[25] Rencoret J., Marques G., Gutiérrez A., Nieto L., JiménezBarbero J., Martínez Á. T., del Río J. C.: Isolation and structural characterization of the milled-wood lignin from Paulownia fortunei wood. Industrial Crops and Products, 30, 137-143 (2009).

https://doi.org/10.1016/j.indcrop.2009.03.004
[26] Qiu X., Kong Q., Zhou M., Yang D.: Aggregation behavior of sodium lignosulfonate in water solution. The Journal of Physical Chemistry B, 114, 15857-15861 (2010). https://doi.org/10.1021/jp107036m

[27] Deng Y., Feng X., Zhou M., Qian Y., Yu H., Qiu X.: Investigation of aggregation and assembly of alkali lignin using iodine as a probe. Biomacromolecules, 12, 11161125 (2011).

https://doi.org/10.1021/bm101449b 